\title{
North Atlantic SST Anomalies and the Cold North European Weather Events of Winter 2009/10 and December 2010
}

\author{
JiAn Buchan, Jö̈l J.-M. Hirschi, AdAM T. Blaker, AND BABlu Sinha \\ National Oceanography Centre, Southampton, United Kingdom
}

(Manuscript received 28 March 2013, in final form 18 September 2013)

\begin{abstract}
Northern Europe experienced consecutive periods of extreme cold weather in the winter of 2009/10 and in late 2010. These periods were characterized by a tripole pattern in North Atlantic sea surface temperature (SST) anomalies and exceptionally negative phases of the North Atlantic Oscillation (NAO). A global oceanatmosphere general circulation model (OAGCM) is used to investigate the ocean's role in influencing North Atlantic and European climate. Observed SST anomalies are used to force the atmospheric model and the resultant changes in atmospheric conditions over northern Europe are examined. Different atmospheric responses occur in the winter of 2009/10 and the early winter of 2010. These experiments suggest that North Atlantic SST anomalies did not significantly affect the development of the negative NAO phase in the cold winter of 2009/10. However, in November and December 2010 the large-scale North Atlantic SST anomaly pattern leads to a significant shift in the atmospheric circulation over the North Atlantic toward a NAO negative phase. Therefore, these results indicate that SST anomalies in November/December 2010 were particularly conducive to the development of a negative NAO phase, which culminated in the extreme cold weather conditions experienced over northern Europe in December 2010.
\end{abstract}

\section{Introduction}

Northern Europe experienced two severe winters in succession in 2009 and 2010. December 2009 to February 2010 was ranked as the coldest winter in western Europe since 1978/79. This was followed by an extremely cold period during December 2010 with the coldest U.K. December temperatures in over 100 years (see http:// www.metoffice.gov.uk/climate/uk/2010/december.html). The leading mode of interannual to decadal variability of the atmosphere over the North Atlantic in winter is the North Atlantic Oscillation (NAO; Hurrell and Deser 2009). The NAO defines the distribution of atmospheric mass between the Arctic and the subtropical Atlantic and swings from positive $(\mathrm{NAO}+)$ to negative $(\mathrm{NAO}-)$ producing large changes in surface air temperatures, storm-track position, and precipitation over the North Atlantic and western Europe. Two other winter climate regimes that display strong anticyclonic ridges over Scandinavia (the "blocking" regime) and off western

\footnotetext{
Corresponding author address: Jian Buchan, National Oceanography Centre, European Way, Southampton SO14 3ZH, United Kingdom.

E-mail: jrb1g10@soton.ac.uk
}

Europe (the "Atlantic Ridge" regime) are also possible (Hurrell and Deser 2009). A number of different mechanisms that could influence the state of the NAO have been proposed. Changes in the rate and location of tropical heating have been shown to influence the atmospheric circulation over the North Atlantic and, in particular, the NAO. Tropical convection, in turn, is sensitive to the underlying SST distribution, which exhibits much more persistence than SST variability in midlatitudes (Hurrell and Deser 2009). Recent modeling work has shown that the atmospheric response to the reemerging North Atlantic SST tripole resembles the phase of the NAO that created the SST tripole the previous winter, thereby modestly enhancing the winterto-winter persistence of the NAO (Cassou et al. 2007).

The phases of the NAO are categorized by the variability in sea level pressure (SLP) over the Northern Hemisphere. The NAO index is defined as the normalized difference between mean SLP measured over Portugal and Iceland. The winters of 2009/10 and 2010/11 recorded extreme negative phases of the NAO, with December 2010 seeing the lowest NAO index (-4.62) since December 1996 and the second lowest December value since records began in 1825 (Osborn 2011). Several mechanisms have been proposed for the anomalously 
low winter temperatures. These include the teleconnection pattern of the Northern Hemisphere and El NiñoSouthern Oscillation (ENSO) and anomalous Eurasian snow cover (Cohen et al. 2010), anomalous Arctic sea ice extent (Strey et al. 2010), and sudden stratospheric warmings (Fereday et al. 2012). The North Atlantic experienced anomalous SSTs during these two winters (Taws et al. 2011) and these are known to influence atmospheric circulation over northern Europe (Cassou et al. 2007).

The relationship between fluctuations in North Atlantic SSTs and the strength of the NAO has long been recognized (Bjerknes 1964; Deser and Blackmon 1993; Sutton and Allen 1997; Czaja and Frankignoul 2002). The patterns of European climate change in the 1990s and 2000s have been linked to the observed warming of the North Atlantic during this period (Hirschi 2008; Sutton and Dong 2012). The influence of North Atlantic SST anomalies on the atmospheric circulation over the North Atlantic during winter has been investigated by performing experiments with atmospheric general circulation models (Grötzner et al. 1998; Davies et al. 1997; Rodwell et al. 1999; Robertson et al. 2000; Cassou et al. 2007; Brayshaw et al. 2011). Rodwell et al. (1999) used observed SST patterns as surface boundary conditions for a global atmospheric model. The simulated temporal evolution of the NAO index was significantly correlated with the observed NAO values especially on interannualto-decadal time scales. Strong spatial correlations were observed between SST anomalies and surface evaporation with increased (decreased) evaporation in regions of positive (negative) SST anomalies resulting in increased (decreased) mean sea level pressure downstream. Robertson et al. (2000) investigated the influence of Atlantic SST anomalies on the atmospheric circulation over the North Atlantic sector during winter by performing experiments with an atmospheric general circulation model. These consisted of a $30-y r$ run with observed SST anomalies for the period 1961-90 confined geographically to the Atlantic Ocean, and a control run with climatological SSTs prescribed globally. Circulation patterns that resemble the positive phase of the NAO became more pronounced in terms of the leading EOF of winter means. Interannual fluctuations in the simulated NAO were found to be significantly correlated with SST anomalies over the tropical and subtropical South Atlantic. The response to North Atlantic SSTs is known to be highly sensitive to the background state (Kushnir et al. 2002). Brayshaw et al. (2011) identified the importance of changes in SST gradients for understanding the atmospheric response to SST anomalies. In their most recent study the impact of the SST structure in the North Atlantic on the storm track and large-scale atmospheric flow was examined using a hierarchy of GCM simulations. Two key regions of the North Atlantic were identified: a western region with a strong meridional temperature gradient across the Gulf Stream and an eastern region in midlatitudes associated with the North Atlantic Drift. Individually a strong Gulf Stream meridional SST gradient in the western North Atlantic was found to strengthen the downstream storm track while the North Atlantic Drift pattern reduces it. When the combined SST pattern is used their results suggested that the North Atlantic storm track is enhanced.

In contrast to these previous studies the aim of the present study is to examine the role played by North Atlantic SSTs on shorter (monthly) time scales. We show that the strength of the feedback from Atlantic SSTs onto the atmospheric circulation can vary by investigating two recent European cold events that both coincided with similarly low NAO values: the winter of $2009 / 10$ and the early winter of 2010/11. We investigate the sensitivity of the atmospheric circulation over the North Atlantic to observed variations in the North Atlantic SST during the winter of 2009/10 and the early winter of 2010 using an ocean-atmosphere model. Observed SST anomalies are applied to the model and the atmospheric responses are analyzed. The method is described in section 2. Observed SST anomalies and their impact on the atmospheric circulation are described in sections 3 and 4 and a discussion of our findings and conclusions are given in section 5 .

\section{Method}

We use observed sea surface temperatures from the National Oceanic and Atmospheric Administration (NOAA) optimum interpolation (OI) SST V2 monthly time series (Reynolds and Smith 1994; Reynolds et al. 2002), which is derived by linear interpolation of the weekly OI version 2 fields to daily fields then averaged over a month. The analysis uses in situ and satellite SSTs and is produced on a $1^{\circ} \times 1^{\circ}$ grid. The SST anomalies that form the basis of our study are obtained by removing the 1981-2010 climatology.

We employ the Fast Ocean Rapid Troposphere Experiment (FORTE) climate model (Sinha and Smith 2002; Blaker et al. 2006; Wilson et al. 2009; Sinha et al. 2012) to perform our numerical experiments. The ocean component of FORTE contains a simple sea ice model and has a horizontal resolution of $2^{\circ} \times 2^{\circ}$ and $15 z$-coordinate layers in the vertical. The model uses the mixing parameterization of Gent and McWilliams (1990). The atmospheric component consists of a T42 spectral atmosphere corresponding to a horizontal resolution of 
approximately $2.8^{\circ} \times 2.8^{\circ}$ and has 15 sigma levels. Both the ocean and the atmospheric components are based on the primitive equations. Coupling between the ocean and atmosphere occurs daily via the Ocean Atmosphere Sea Ice Soil (OASIS; Valcke et al. 2000) coupler. The absence of a stratosphere in FORTE is likely to reduce possible atmospheric teleconnections between the tropical Pacific and the North Atlantic region (Bell et al. 2009).

Starting from rest with the Levitus (temperature, salinity) climatology (Levitus and Boyer 1998; Levitus et al. 1998) the model is spun up for 100 years prior to the main experiments. During this period the ocean reaches a quasi-steady state. The model is then run on for an additional 100 years to generate a control simulation for the subsequent experiments. Henceforth, this experiment will be referred to as "CONTROL." For the whole duration of CONTROL we save the SSTs and the fluxes exchanged daily between the ocean and atmosphere. Every two years a restart file, corresponding to 1 January, is generated that provides us with a set of 50 different initial atmospheric conditions from where we can start further experiments. Based on the restart files for the atmosphere we then perform two sets of 50 24-month-long experiments. In these ensemble experiments the SSTs are prescribed with no feedback from the atmosphere onto the ocean. The prescribed SSTs consist of the stored SSTs from CONTROL to which we add the observed SST anomalies from the NOAA OISST dataset for the 24 months from January 2009 to December 2010. We also conducted a simulation using the unmodified CONTROL SSTs, confirming that the response of the atmosphere is identical to the original and that there was no "decoupling" effect in the simulations. The two ensemble experiments with prescribed SSTs differ in the area over which we apply observed SST anomalies. In ensemble SSTA we use observed monthly mean Atlantic SST anomalies covering the Atlantic region from $30^{\circ} \mathrm{S}$ to $80^{\circ} \mathrm{N}$. The second ensemble GSSTA repeats the previous experiment using observed global SST anomalies for the same period. The ensembles SSTA and GSSTA allow us to isolate the influence of North Atlantic SST anomalies and to establish if they were the main contributor to the atmospheric response.

\section{Sea surface temperature anomalies winter 2009 and 2010}

The global SST anomalies for December 2009 and December 2010 are first examined to identify similarities and differences between the two winters (Fig. 1). Both winters were characterized by a tripole pattern in North Atlantic SST anomalies. Cold anomalies in the

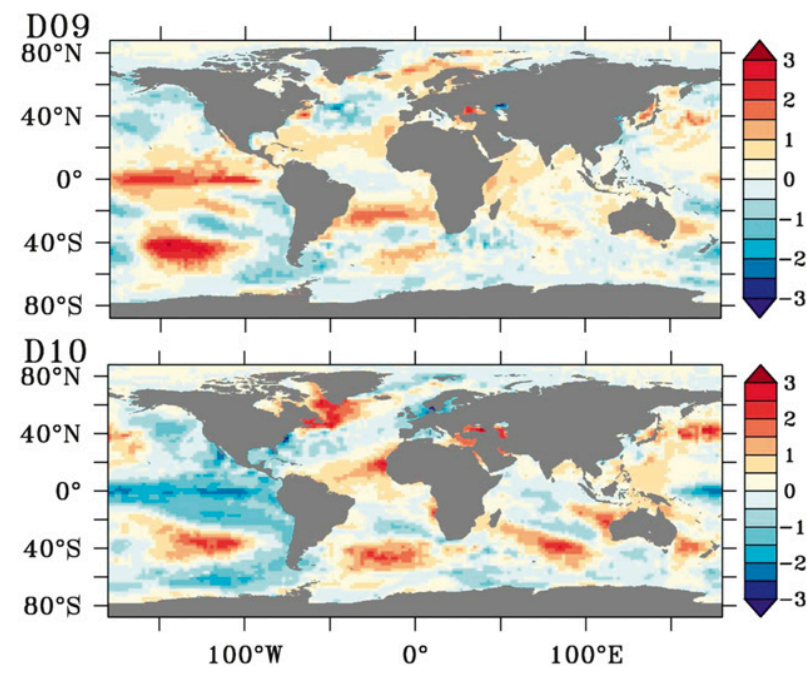

FIG. 1. Global SST anomalies $\left({ }^{\circ} \mathrm{C}\right)$ from NOAA OI v2 SST data for (top) December 2009 (D09) and (bottom) December 2010 (D10).

mid-subtropical North Atlantic were flanked by warm anomalies to the south and north. In the Pacific the warm anomalies from an El Niño event (Niño-3 index = 1.6) in 2009 are replaced by cold anomalies from a La Niña (Niño-3 index $=-1.5$ ) event in 2010.

A more detailed examination of North Atlantic SST anomalies for December 2009 and December 2010 (Fig. 2) reveals more pronounced SST anomalies in 2010. While both winters have the characteristic tripole pattern of cold SST anomalies in the central Atlantic between $30^{\circ}$ and $50^{\circ} \mathrm{N}$ and between $70^{\circ}$ and $20^{\circ} \mathrm{W}$ in 2009 , this extends to the west and south in 2010 from $20^{\circ} \mathrm{N}$, $80^{\circ} \mathrm{W}$. Warm SST anomalies over the Labrador Sea in 2009 intensify and extend south and west in 2010 to $45^{\circ} \mathrm{N}, 30^{\circ} \mathrm{W}$. The warm SST anomalies in the southeastern tropical Atlantic extended westward from $20^{\circ}$ to $40^{\circ} \mathrm{W}$ in 2010.

Part of the cold SST anomaly signal from the winter 2009/10 persisted beneath the seasonal thermocline and the subsurface anomaly pattern subsequently reemerged during late autumn and early winter 2010 (Taws et al. 2011) as clearly seen in panels F10 and D10 of Fig. 2. Reemergence is the process whereby ocean temperature anomalies established in a deep winter mixed layer are sequestered beneath the seasonal thermocline in the summer and reappear at the surface as the mixed layer deepens during the following winter season (Alexander and Deser 1995).

The developing pattern of North Atlantic SST anomalies in November and December 2010 shows the reemergence of an enhanced tripole pattern from February 2010 (Taws et al. 2011). The large-scale spatial features reveal cold anomalies of $-0.5^{\circ}$ to $-1.5^{\circ} \mathrm{C}$ in the central North Atlantic with warm anomalies to the north and 

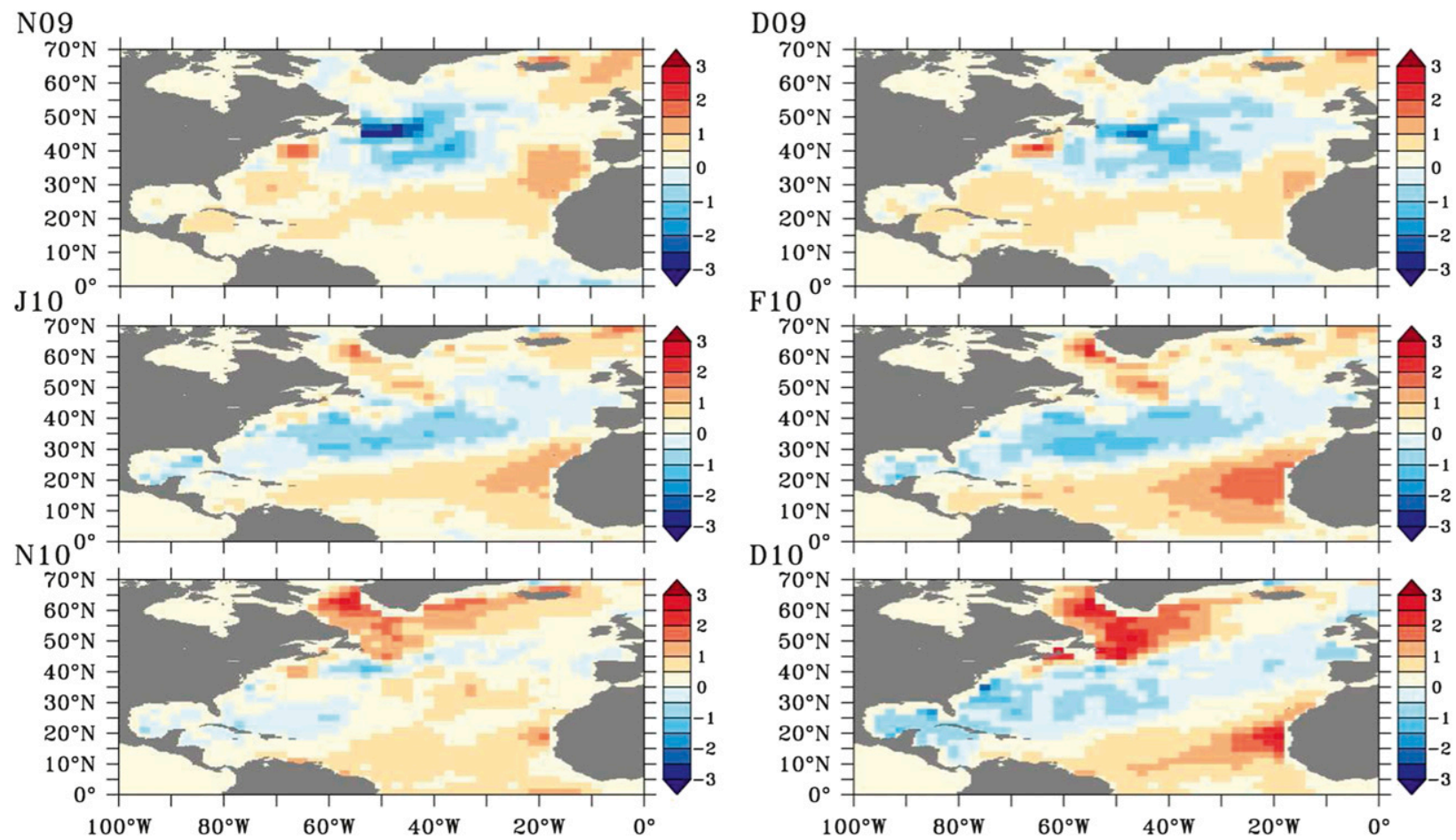

FIG. 2. North Atlantic SST anomalies $\left({ }^{\circ} \mathrm{C}\right.$ ) from NOAA OI v2 SST data for November 2009 (N09), December 2009 (D09), January 2010 (J10), February 2010 (F10), November 2010 (N10), and December 2010 (D10).

south. The most pronounced changes between December 2010 and December 2009 are seen in the Labrador and Irminger Sea Basins with significantly higher temperature anomalies in December $2010\left(>1.5^{\circ} \mathrm{C}\right)$ while negative anomalies in the western subtropical Atlantic $\left(20^{\circ}-40^{\circ} \mathrm{N}, 80^{\circ}-60^{\circ} \mathrm{W}\right)$ are more pronounced (down to $-1.5^{\circ} \mathrm{C}$ ). The remote influences of a moderate-to-strong La Niña, developing within the equatorial Pacific in 2010 may have influenced the strength of positive SST anomalies apparent in the tropical Atlantic (Enfield and Mayer 1997).

The SST anomalies in the North Atlantic in December 2010 are significant and were compared to the standard deviations found in both the variability in observed SSTs over a 30-yr period (1981-2010) and the free-running model. In the Atlantic the SST anomalies were within three standard deviations of the variability in observed SSTs over a 30-yr period whereas they were within four standard deviations of the modeled SSTs over the 100-yr CONTROL (Fig. 3).

\section{Atmospheric responses to observed SST anomalies}

First we describe the atmospheric SLP and surface air temperature (SAT) anomalies occurring during positive and negative NAO phases in CONTROL. The impact of
SST anomalies on the NAO is then assessed by looking at the differences in SLP and SAT between the SSTA and CONTROL ensembles. The NAO index is calculated from the difference of the normalized SLP between Lisbon, Portugal $\left(38^{\circ} \mathrm{N}, 9^{\circ} \mathrm{W}\right)$, and Stykkisholmur, Iceland $\left(64^{\circ} \mathrm{N}, 22^{\circ} \mathrm{W}\right.$; Hurrell and Deser 2009), for the CONTROL and SSTA ensembles. We then compare the

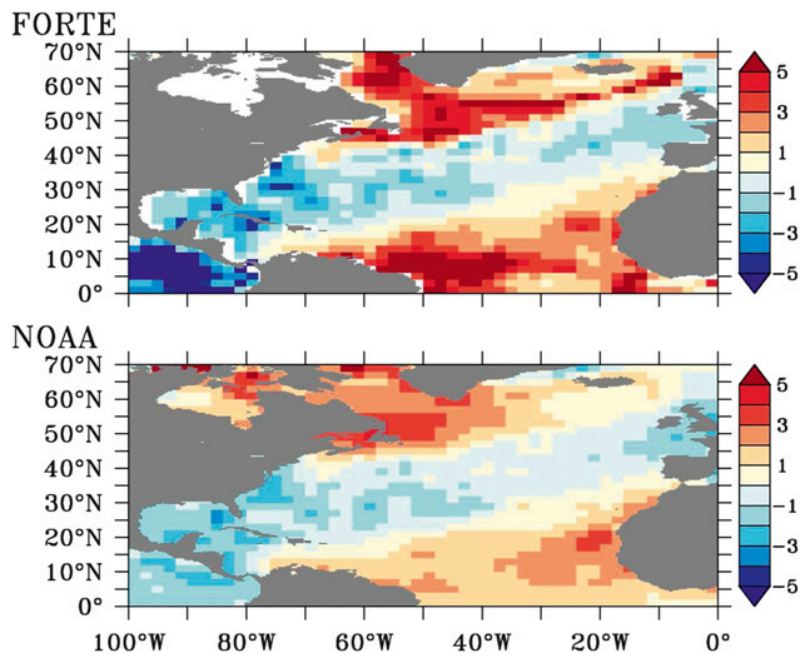

FIG. 3. The ratio of SST anomalies for December 2010 relative to the standard deviations from the (top) FORTE CONTROL ensemble and (bottom) NOAA OI observations. 

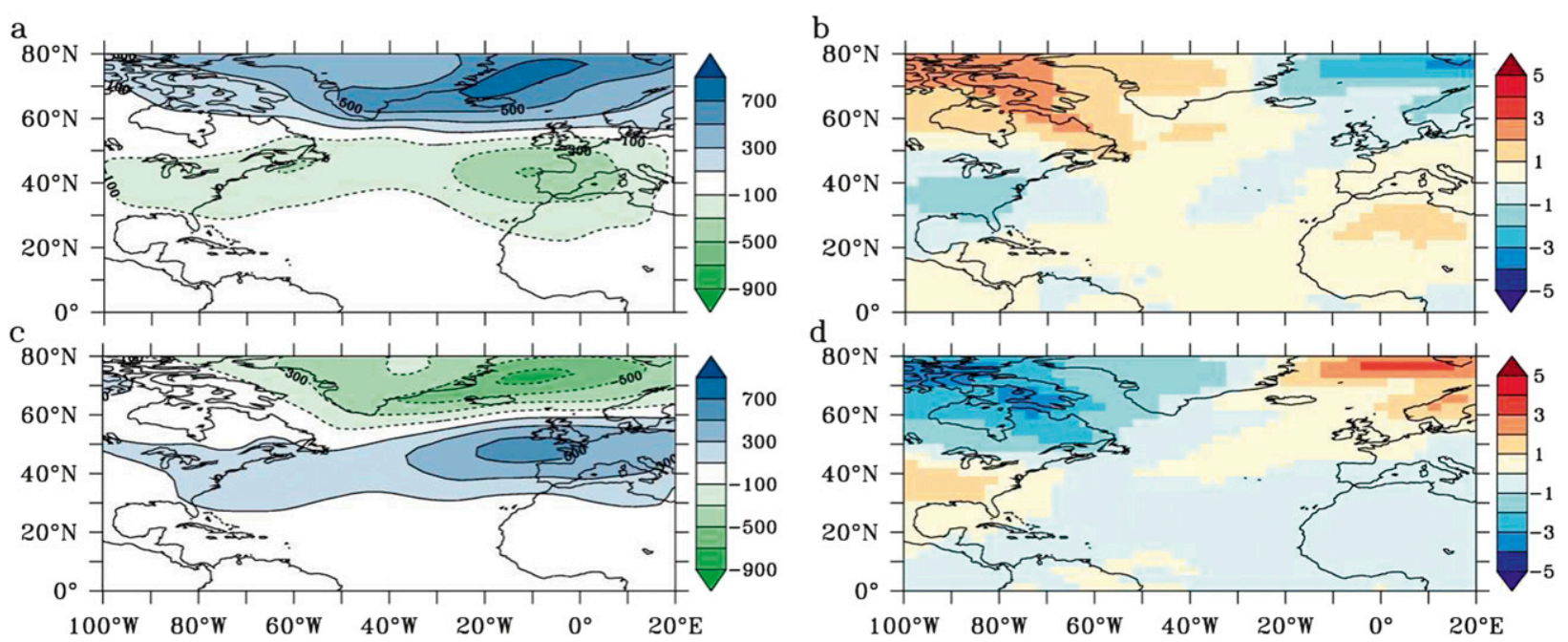

FIG. 4. (a) Composite SLP anomaly (Pa) and (b) composite SAT anomaly $\left({ }^{\circ} \mathrm{C}\right)$ for December 2010 from CONTROL for NAO negative responses. (c) Composite SLP anomaly and (d) composite SAT anomaly for NAO positive responses.

distribution and means of the NAO indices for 2009 and 2010 for the CONTROL and SSTA ensembles.

\section{a. Patterns of atmospheric pressure and surface atmospheric temperature}

The characteristic SLP and SAT patterns for positive and negative NAO phases in the CONTROL experiment are established by calculating anomalies from the ensemble mean for each month of the 2-yr simulations. We initially examine the patterns of SLP and SAT in the CONTROL ensemble for each 24th month (December of the second simulated year). The patterns of SLP and SAT anomalies from the CONTROL and SSTA ensembles are grouped into those with NAO indices, which were greater than 1 or less than -1 . We compute composite anomalies from the CONTROL and SSTA ensemble based on positive or negative values of the NAO index. The SLP composites are calculated according to

$$
\operatorname{SLPA}_{i, j}^{+}=\frac{1}{n} \sum_{l \in l+} \operatorname{SLPA}_{i, j, l^{+}} \text {, }
$$

$n, l+:$ set of time indices and number of $\mathrm{NAO}+$ months,

$$
\mathrm{SLPA}_{i, j}^{-}=\frac{1}{n} \sum_{l \in l-} \mathrm{SLPA}_{i, j, l^{-}}
$$

$n, l-:$ set of time indices and number of NAOmonths,

where $i, j$ are the zonal and meridional gridcell indices from the FORTE data, and where $l$ is index number of the ensemble member.
$\mathrm{NAO}$ - responses are characterized by a positive pressure anomaly centered over Iceland and a negative pressure anomaly centered over Portugal. The pressure anomalies are reversed in NAO+ responses (Fig. 4). The atmospheric circulation patterns from the CONTROL ensemble are reasonably well resolved but model biases are present, which have been previously reported (Wilson et al. 2009). Compared with observations the westerly storm track is too broad to the north and extends too far into Europe. However, a comparison of the general structure of the large scale pressure fields from CONTROL and the National Centers for Environmental Prediction-National Center for Atmospheric Research (NCEP-NCAR) observations showed the locations of the centers of the SLP anomalies from EOF analysis were similar and there was a good correlation between the NAO locations from the CONTROL and observations, as evidenced in Fig. 4. The NAO surface impacts in the SSTA experiment are stronger in CONTROL possibly as a result of the size of the SST anomalies lying at the outer bounds of the model variability and because the ensemble sizes are smaller.

In the NAO - state SATs are cooler over the United Kingdom and northwestern Europe and warmer over southeastern Europe. In the NAO+ state the polarity is reversed with a warming of SATs over northwestern Europe and a cooling over southeastern Europe. These atmospheric circulation patterns from the CONTROL are used to reference the responses in the SSTA ensemble.

We now investigate the atmospheric responses from the SSTA ensemble. Initially composites in the 24th month are compared with those from the CONTROL (month 24 in the ensemble is the month that experiences 

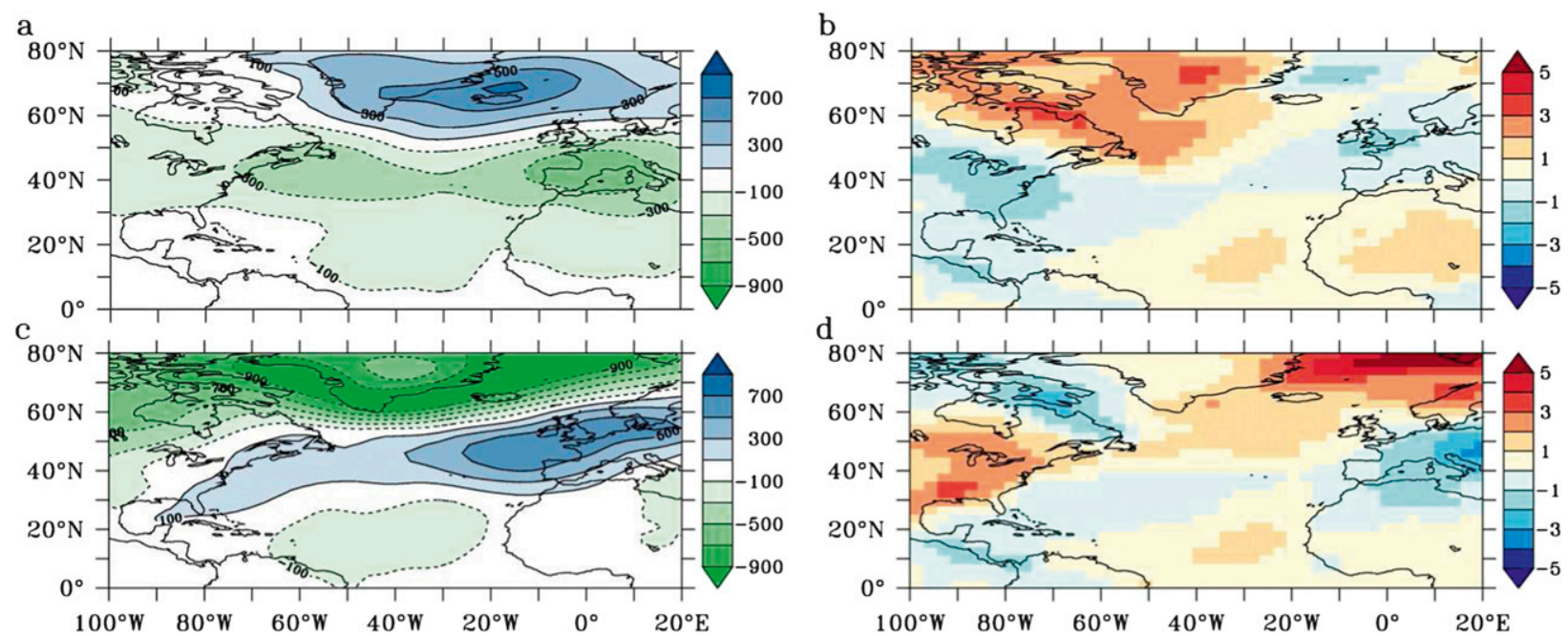

FIG. 5. (a) Composite SLP anomaly (Pa) and (b) composite SAT anomaly $\left({ }^{\circ} \mathrm{C}\right)$ for December 2010 from SSTA for NAO negative responses. (c) Composite SLP anomaly and (d) composite SAT anomaly for NAO positive responses.

the observed December 2010 SST anomalies; Fig. 5). Of the 50 ensemble members of SSTA, 21 exhibit an NAO - state with a positive pressure anomaly over Iceland and a negative pressure anomaly over Lisbon (Figs. 5a,b). An NAO+ state is present in five cases (Figs. 5c,d). The remaining 24 cases produced responses that are NAO neutral where the index is between -1 and 1. For comparison the distribution in the CONTROL ensemble has 17 negative, 23 positive, and 10 neutral cases. The atmospheric circulation patterns for the NAO - members of the SSTA ensemble produced a more widespread cooling of SAT by about $1^{\circ} \mathrm{C}$ over western Europe and a more pronounced warming over Greenland. The position of the centers of the temperature anomalies remains similar to that of the CONTROL ensemble. The NAO + ensemble members show a more pronounced warming of SAT over northwestern Europe and cooling over southeastern Europe.

The NAO+ and NAO- members of the SSTA ensemble also show characteristic differences in atmospheric circulation patterns. $\mathrm{NAO}+$ and $\mathrm{NAO}-$ phases are characterized by shifts in the position of the jet stream. The position of the jet stream from the mean CONTROL atmospheric velocities at $300-\mathrm{hPa}$ geopotential height is centered around $40^{\circ} \mathrm{N}$ (Fig. 6a). The influence of the SST anomalies from December 2010 in the NAO- ensemble is to shift the position of the jet stream southward with lower velocities over northern Europe and higher velocities over southern Europe (Fig. 6b). This shift is consistent with the pressure field for negative phases of the NAO (Rogers 1996). The changes in surface heat fluxes between those in the SSTA NAO - ensemble and mean control conditions show the impact of higher SST anomalies in the northwestern Atlantic in December 2009 and 2010 (Fig. 7). The influence of the SST anomalies in December 2010 compared with December 2009 is particularly significant in the changes in latent heat fluxes to the east of the Labrador/Irminger Sea Basins where the positive SST anomalies lead to higher heat loss from the ocean to the atmosphere. The heat flux anomalies in Fig. 7 lie between the northern two poles in the tripole at $45^{\circ} \mathrm{N}$ in a region where the SST anomalies collectively most weaken the background meridional SST gradient between northern mid- and high latitudes, as can be seen from the SST contours. We expect this to reduce storm activity downstream (consistent with weaker surface baroclinicity) and weaken the surface eddy-driven jet or shift it equatorward (reduced poleward eddy momentum transport in the upper troposphere and reduced poleward eddy heat transport in the mid- to lower troposphere) resulting in the weakening of surface westerlies (Brayshaw et al. 2011). This would have the impact of weakening the downstream storm track over the North Atlantic at $45^{\circ} \mathrm{N}$ and strengthening it at lower latitudes as seen in Fig. 6.

\section{b. Frequency in the occurrence of negative $N A O$ indices}

The results described in the previous section suggest an increased frequency of NAO- phases for months experiencing the SST anomalies from December 2010 in the ensemble SSTA (21 NAO- responses vs $5 \mathrm{NAO}+$ responses). However, does this represent a significant shift toward an NAO- state or can we expect a similar response to happen by chance? To address this question 


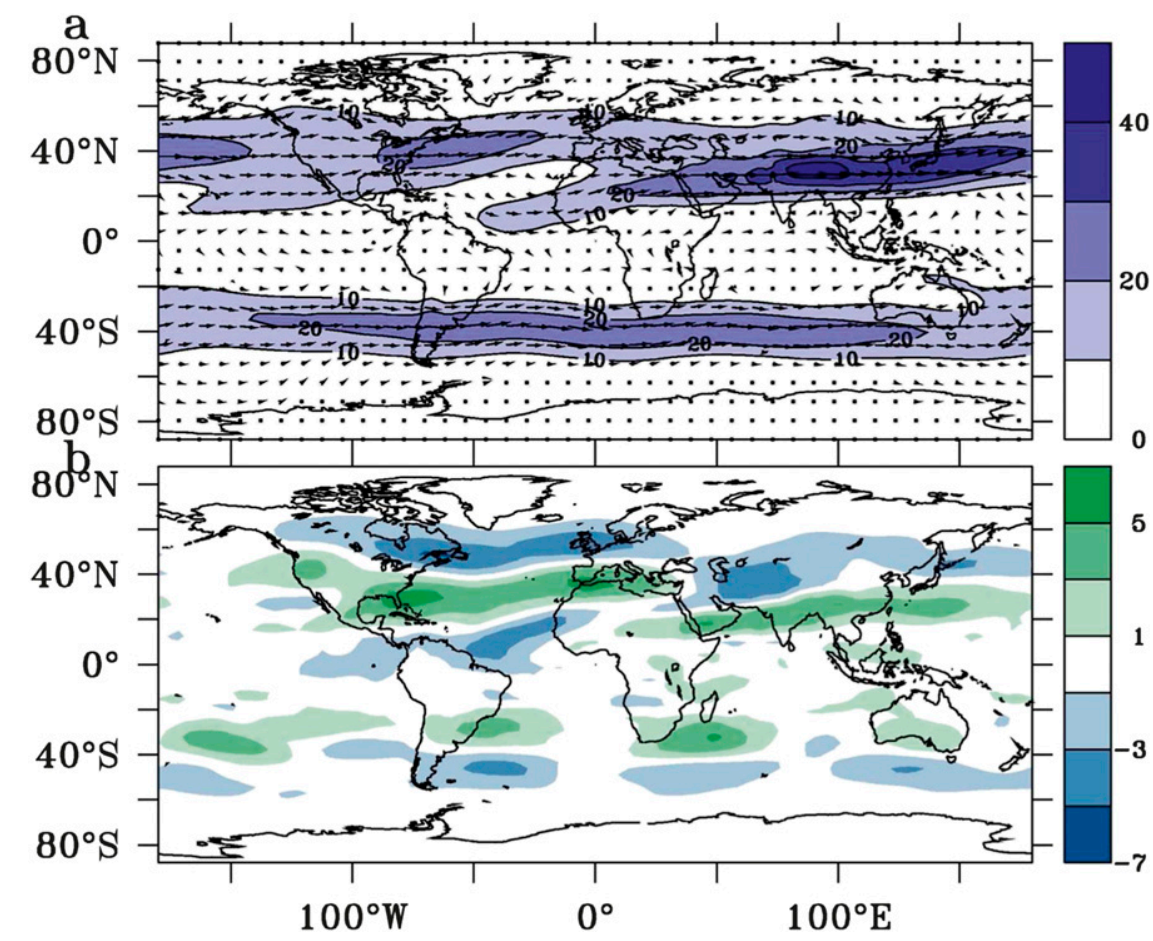

FIG. 6. (a) Mean CONTROL atmospheric velocities at 300-hPa geopotential height $\left(\mathrm{m} \mathrm{s}^{-1}\right)$ for December 2010 with mean wind speeds superimposed. (b) Difference in atmospheric velocities at $300 \mathrm{hPa}$ between SSTA NAO negative ensemble and CONTROL for December $2010\left(\mathrm{~m} \mathrm{~s}^{-1}\right)$.

we assess to what extent the response of the NAO to SST anomalies is statistically significant and how the level of significance for December 2010 compares to the other 23 months of the $2009-10$ period.

The occurrences of atmospheric conditions representative of NAO- phases in the CONTROL and SSTA ensembles are tested by examining the mean NAO indices for a particular month in the 24-month simulation to establish if SST anomalies influence the frequency of atmospheric patterns. We start by comparing the distributions of NAO indices in the 24th month (December 2010) for both the CONTROL and SSTA ensembles. The results indicate a pronounced shift to negative NAO indices in the SSTA ensemble as evidenced by both the ensemble mean and overall distribution (Fig. 8). The CONTROL ensemble has a mean NAO index for month 24 (December 2010) of -0.08 whereas the SSTA ensemble has a mean of -1.1 . The SSTA ensemble has 21 outcomes with a mean NAO index less than -1 and only 5 with a mean NAO index greater than +1 .

The significance of this result was tested by comparing the mean from the SSTA ensemble against the means of 100000 random composites of the CONTROL ensemble using 50 samples chosen randomly for December with replacement (Fig. 9). As expected, the means of the
NAO taken from the randomly selected composites of the CONTROL ensemble were normally distributed around an NAO index of -0.08 . The distribution was further tested using the central limit theorem to create the distribution from the mean and standard deviation from month 24 of the CONTROL ensemble. The result shows good agreement with the distribution from the random composites confirming the two datasets to have the same distribution. Comparing the distribution to the mean NAO index of the SSTA ensemble reveals that the value of -1.1 is significant. We expect to find a mean NAO index of -1.1 or less in fewer than 1 in 1000 randomly chosen 50-member ensembles. The shift toward negative NAO values for December 2010 is statistically significant and very unlikely to have occurred by chance.

A similar level of significance is obtained for the ensemble global SST anomaly (GSSTA) where we prescribe global SST anomalies (mean NAO index of -1.0). However, ENSO teleconnections reliant on the stratosphere cannot be represented in this model and we are unable to determine if tropical Pacific SST anomalies contributed to a response in the NAO in our experiments.

So far our analysis has concentrated on the NAO response occurring in December 2010. However, 


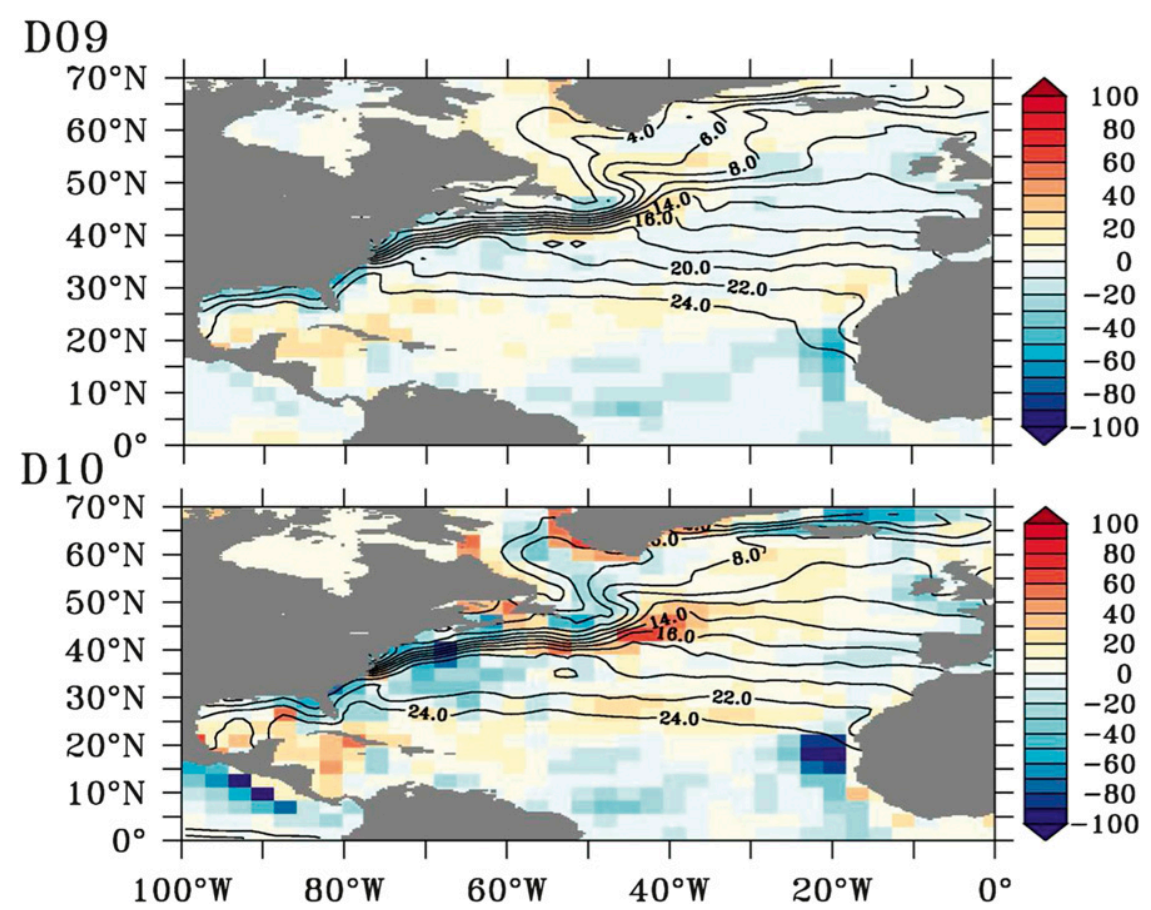

FIG. 7. Surface upward total heat flux anomalies $\left(\mathrm{W} \mathrm{m}^{-2}\right)$ between SSTA NAO negative ensemble and control mean for (top) December 2009 and (bottom) December 2010. Contours show SST for December 2009 and December $2010\left({ }^{\circ} \mathrm{C}\right)$.

pronounced SST anomalies also occurred in other months of the 2009-10 period (e.g., during the winter of 2009/10, see Fig. 2). Is the response we find for December 2010 unusual compared to the responses for the other 23 months? To answer this question we compare the mean monthly NAO indices for every month in the 24-month simulations in the SSTA, GSSTA, and CONTROL ensembles (Fig. 10). The monthly mean of the NAO index in the SSTA and GSSTA ensembles is compared with the corresponding monthly mean found in CONTROL. Even though the NAO extremes for each of the 24 months are similar in the ensembles SSTA and CONTROL the monthly means of the NAO index remain close to 0 in CONTROL. In contrast we find significant shifts in the NAO index for several months in the SSTA and GSSTA ensembles (i.e., shifts in excess of two standard deviations from monthly random composites of the CONTROL ensemble). A weak NAO response is seen in months 11 and 12 (corresponding to November and December 2009) coincident with the first episode of North Atlantic SST anomalies. However, the NAO response is always weaker than for months 23 and 24 (corresponding to November and December 2010), which were both influenced by reemerging SST anomalies (Taws et al. 2011). The negative NAO response for November 2010 is almost as strong as that found for December 2010. This is consistent with the observed values of the NAO index, which started its dip toward record low values in November 2010.

We note that applying observed SST anomalies in experiment SSTA has little impact on the spread of the values of the NAO index (Fig. 10). As mentioned above the extreme values of the NAO index are similar in CONTROL and SSTA. In addition, we find that for all
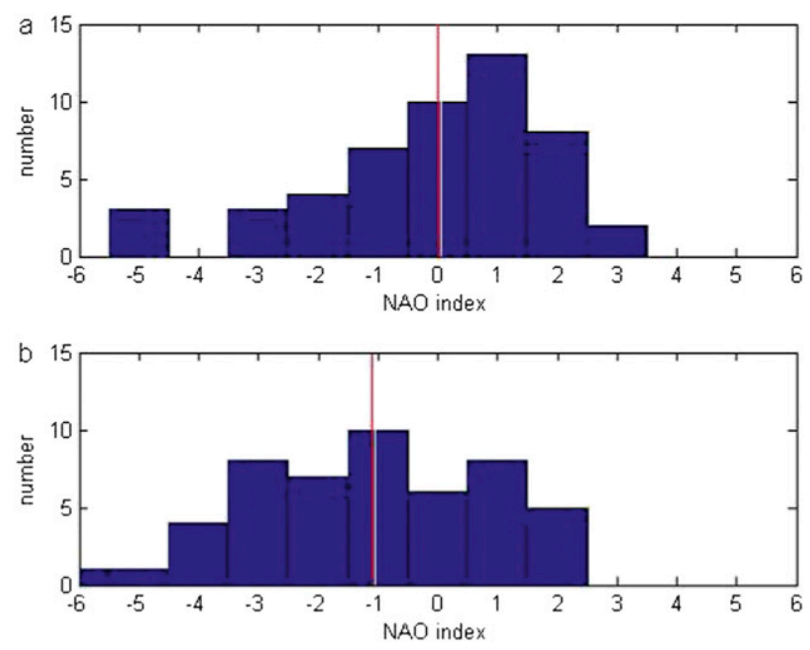

FIG. 8. Distribution of NAO indices for December 2010 in the (a) CONTROL and (b) SSTA ensembles. Red lines show the ensemble mean. 


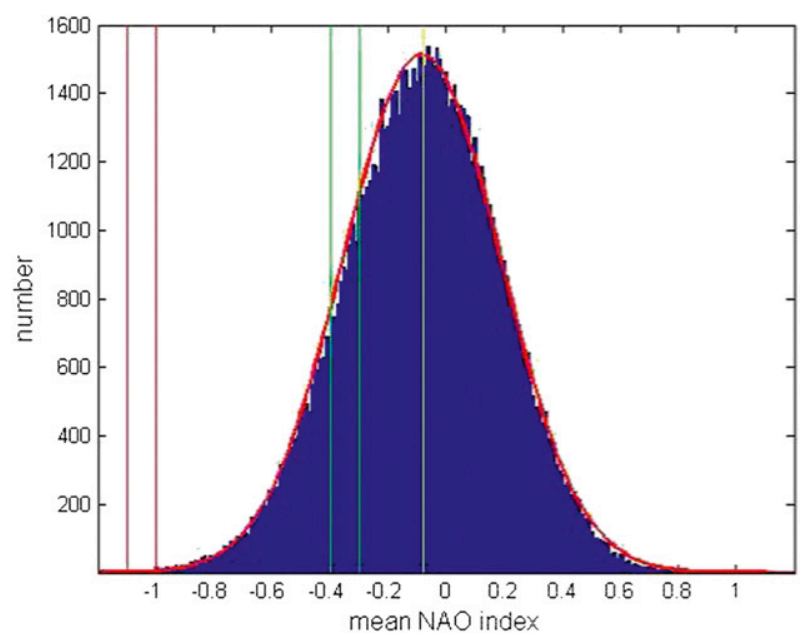

FIG. 9. Distribution of mean NAO index for December 2010 for 100000 composites of 50 samples taken randomly from the CONTROL ensemble. CONTROL mean $(-0.05)$ (yellow), SSTA mean November $2010(-1.0)$ and December 2010 (-1.1) (red), and November $2009(-0.3)$ and December $2009(-0.4)$ (green). The distribution calculated from the mean and standard deviation from the CONTROL ensemble for December 2010 is shown in red.

months the first and third quartiles for the values of the NAO index are comparable in SSTA and CONTROL (and also in GSSTA; not shown). Both the extreme values of the NAO index and the quartiles show a seasonal cycle with a larger spread of values occurring in winter and spring than in summer and autumn. This reflects the higher variability of the atmosphere and therefore of the NAO index that characterizes the boreal winter season. The similarity in the spread of NAO values in CONTROL and SSTA is a strong indication that the shifts seen for the mean value of the NAO index (Fig. 10) are not the consequence of increased variability in the NAO index in SSTA compared to CONTROL. In summary, our results suggest that the SST anomalies in November and December 2010 were more conducive to the development of a negative NAO than those in the preceding cold European winter of 2009/10.

\section{Discussion and conclusions}

Earlier studies have illustrated that Atlantic SSTs affect the evolution of the NAO on interannual to decadal time scales (e.g., Rodwell et al. 1999; Robertson et al. 2000). Here in contrast our focus is on shorter (monthly) time scales and we show that the strength of the feedback from Atlantic SSTs onto the atmospheric circulation can vary by investigating two recent European cold events that both coincided with similarly low NAO values: the winter of $2009 / 10$ and the early winter of

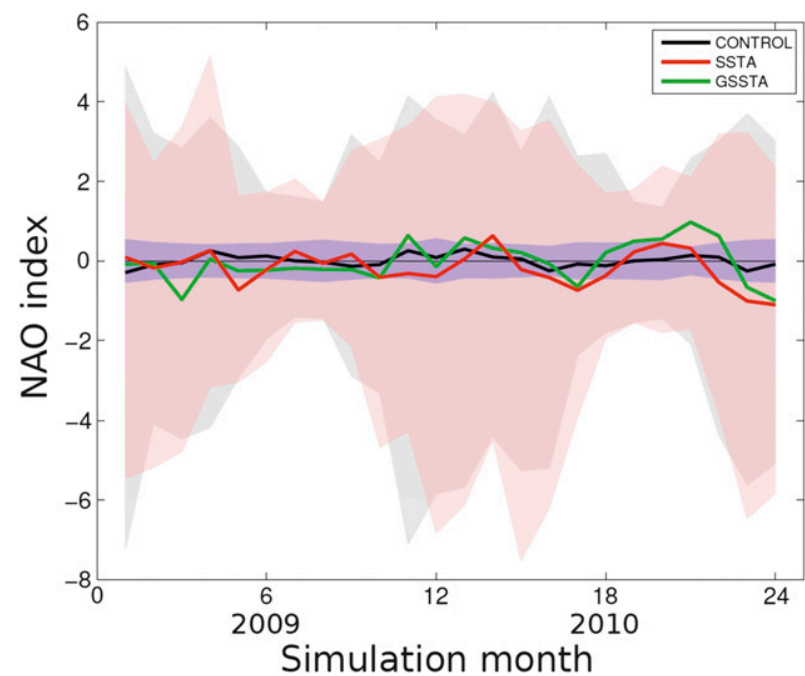

FIG. 10. Mean monthly NAO indices for CONTROL (black), SSTA (red), GSSTA (green), and two standard deviations of monthly mean NAO index sampled randomly from CONTROL (blue). Shaded areas denote the range (maximum and minimum) for each of the 24 months in the CONTROL (black) and SSTA (red) ensembles.

2010/11. Our results suggest that North Atlantic SST anomalies significantly increased the probability of changes in atmospheric circulation affecting Europe in late 2010, but that they had a smaller impact in the preceding winter of 2009/10. Our findings also suggest that the tropical SST anomalies observed in the Pacific are unlikely to have caused the NAO responses observed in the early winter of 2010/11. Positive SST anomalies in the Labrador/Irminger Sea Basins and negative SST anomalies in the subtropical North Atlantic result in changes in the atmospheric pressure structure. The jet stream is deflected southward giving rise to a band of low pressure in the Azores around $40^{\circ} \mathrm{N}$ and high pressure over Iceland resembling a NAO- mode (Rodwell et al. 1999).

The absence of a stratosphere in our model limits our ability to model the possible atmospheric teleconnections between the tropical Pacific and the North Atlantic region, although such teleconnections would be expected to operate later in the winter (Bell et al. 2009). We also note that the SST anomalies experienced in SSTA and GSSTA can be outside the range of the SST variability of CONTROL. This happens since we add the observed SST anomalies to the SSTs of CONTROL, which increases the SST variance.

However, this does not affect our main findings. While the applied SST field in ensemble SSTA/GSSTA can be outside the model's natural variability range the use of observed SST anomalies over the 24-month period provides a comparison of the atmospheric responses 
over that period. The range of variability and distribution of NAO values in SSTA and CONTROL over the 24 months are similar, which indicates that the use of observed SST anomalies in the model produce results that are still within the bounds of the natural atmospheric variability of the coupled model (Fig. 10). The prescribing of observed SST anomalies in uncoupled atmosphere experiments has been used in other studies (e.g., Kushnir et al. 2002; Jung et al. 2011). While the size of the NAO response could be influenced by the scale of the SST anomalies our experiments show a larger atmospheric response for November/December 2010 than for any of the other months of the 2009-10 period. In particular, our study indicates that anomalous SSTs over the North Atlantic region contributed toward forcing the atmosphere toward a negative NAO state in the early winter of 2010/11.

Our results should not be interpreted as the ocean being the sole driver for the extreme cold event in the early winter of 2010/11. As mentioned earlier an interesting aspect of our results is the indication that SST anomalies occurring during similarly negative NAO phases (as observed during the cold winter of 2009/10 and in late 2010) do not necessarily have the same impact on the atmosphere. The strongly NAO- atmospheric circulation pattern that coincided with both periods is itself consistent with the development of an anomalous SST tripole pattern in the North Atlantic (Czaja and Frankignoul 2002). However, our results suggest that in late 2010 coupled ocean-atmosphere processes over the North Atlantic were particularly important. This is illustrated by the different atmospheric responses we find for the winter of 2009/10 and for late 2010. Both phases coincided with pronounced NAO - phases and an anomalous SST tripole in the North Atlantic. However, in late 2010 the SST anomalies were significantly more pronounced particularly over the Labrador/Irminger Sea Basins with anomalous heat flux lying between the northern two poles in the tripole at $45^{\circ} \mathrm{N}$ weakening the background equator-topole SST gradient. We would expect this to reduce storm activity downstream, weakening the surface eddydriven jet or shifting it equatorward and weakening the surface westerlies at this latitude. The stronger NAO responses to November/December 2010 SST anomalies compared to the response found in the winter of 2009/10 suggest that the conditions in the early winter 2010/11 were significantly influenced by coupled ocean-atmosphere processes, whereas in 2009/10 the strong NAO- pattern is more likely to reflect internal variability of the atmosphere with the ocean playing a more passive role.

The implication of our results is that the ocean can play an important role in the genesis of certain extreme weather events in the North Atlantic region. The years 2009 and 2010 were particularly interesting from an oceanic point of view. An observing system in the North Atlantic registered a marked decrease of the strength of the Atlantic meridional overturning circulation (AMOC) in 2009 (McCarthy et al. 2012; Rayner et al. 2011). The AMOC is highly correlated to the oceanic northward transport of heat (Johns et al. 2011) and the period of reduced AMOC coincided with a reduction in the North Atlantic ocean heat content (OHC) in late 2009 (Sonnewald et al. 2013). Alongside anomalous Eurasian snow cover (Cohen et al. 2010) and anomalous Arctic sea ice extent (Strey et al. 2010; Liu et al. 2012), the reduced ocean heat transport may have contributed to the buildup of a negative $\mathrm{OHC}$ anomaly during the severe winter of 2009/10, which subsequently reemerged in the early winter of 2010/11 (Taws et al. 2011).

At this stage the sequence of events described above is speculative. Nevertheless, the evidence presented here indicates that simulations of the NAO are influenced by the pattern of ocean surface temperatures occurring in October-December 2010. Our conclusion is that reemergence of SST anomalies in the North Atlantic contributed toward the development of an SST anomaly pattern, which favored the persistence of a negative NAO resulting in the cold weather anomaly of December 2010 in northern Europe.

Acknowledgments. The authors thank David Brayshaw and an anonymous reviewer for their thoughtful reviews and comments, which helped to improve this paper. This work was part of the NERC funded project MONACO. Joel Hirschi, Bablu Sinha, and Adam Blaker are supported by National Capability funding provided by the United Kingdom Natural Environment Research Council.

\section{REFERENCES}

Alexander, M. A., and C. Deser, 1995: A mechanism for the recurrence of wintertime midlatitude SST anomalies. J. Phys. Oceanogr., 25, 122-137.

Bell, C. J., L. J. Gray, A. J. Charlton-Perez, and M. M. Joshi, 2009: Stratospheric communication of El Niño teleconnections in European winter. J. Climate, 22, 4083-4096.

Bjerknes, J., 1964: Atlantic air-sea interaction. Advances in Geophysics, Vol. 10, Academic Press, 1-82.

Blaker, A. T., B. Sinha, V. O. Ivchenko, N. C. Wells, and V. B. Zalesny, 2006: Identifying the roles of the ocean and atmosphere in creating a rapid equatorial response to a Southern Ocean anomaly. Geophys. Res. Lett., 33, L06720, doi:10.1029/2005GL025474.

Brayshaw, D. J., B. Hoskins, and M. Blackburn, 2011: The basic ingredients of the North Atlantic storm track. Part II: Sea surface temperatures. J. Atmos. Sci., 68, 1784-1805.

Cassou, C., C. Deser, and M. A. Alexander, 2007: Investigating the impact of reemerging sea surface temperature anomalies 
on the winter atmospheric circulation over the North Atlantic. J. Climate, 20, 3510-3526.

Cohen, J., J. Foster, M. Barlow, K. Saito, and J. Jones, 2010: Winter 2009-2010: A case study of an extreme Arctic Oscillation event. Geophys. Res. Lett., 37, L17707, doi:10.1029/2010GL044256.

Czaja, A., and C. Frankignoul, 2002: Observed impact of Atlantic SST anomalies on the North Atlantic Oscillation. J. Climate, 15, 605-623.

Davies, J. R., D. P. Rowell, and C. K. Folland, 1997: North Atlantic and European seasonal predictability using an ensemble of multidecadal atmospheric GCM simulations. Int. J. Climatol., 17, 1263-1284.

Deser, C., and M. L. Blackmon, 1993: Surface climate variations over the North Atlantic during winter: 1900-1989. J. Climate, 6, 1743-1753.

Enfield, D. B., and D. A. Mayer, 1997: Tropical Atlantic sea surface temperature variability and its relation to El Niño-Southern Oscillation. J. Geophys. Res., 102 (C1), 929-945.

Fereday, D. R., A. Maidens, A. Arribas, A. A. Scaife, and J. R. Knight, 2012: Seasonal forecasts of Northern Hemisphere winter 2009/10. Environ. Res. Lett., 7, 034031, doi:10.1088/ 1748-9326/7/3/034031.

Gent, P. R., and J. C. McWilliams, 1990: Isopycnal mixing on Ocean Circulation Models. J. Phys. Oceanogr., 20, 150-160.

Grötzner, A., M. Latif, and T. P. Barnett, 1998: A decadal climate cycle in the North Atlantic Ocean as simulated by the ECHO coupled GCM. J. Climate, 11, 831-847.

Hirschi, J. J.-M., 2008: Unusual North Atlantic temperature dipole during the winter of 2006/2007. Weather, 63, 1, 4-11.

Hurrell, J. W., and C. Deser, 2009: North Atlantic climate variability: The role of the North Atlantic Oscillation. J. Mar. Syst., 78, 28-41, doi:10.1016/jmarsys.2008.11.026.

Johns, W. E., and Coauthors, 2011: Continuous, array-based estimates of Atlantic Ocean heat transport at $26.5^{\circ} \mathrm{N}$. J. Climate, 24, 2429-2450.

Jung, T., F. Vitart, L. Ferranti, and J.-J. Morcrette, 2011: Origin and predictability of the extreme negative NAO winter of 2009/10. Geophys. Res. Lett., 38, L07701, doi:10.1029/2011GL046786.

Kushnir, Y., W. A. Robinson, I. Blade, N. M. J. Hall, S. Peng, and R. Sutton, 2002: Atmospheric GCM response to extratropical SST anomalies: Synthesis and evaluation. J. Climate, 15, 2233-2256.

Levitus, S., and T. P. Boyer, 1998: Temperature. Vol. 4, World Ocean Atlas 1998, NOAA Atlas NESDIS 4, 99 pp.

—, R. Burgett, and T. P. Boyer, 1998: Salinity. Vol. 3, World Ocean Atlas 1998, NOAA Atlas NESDIS 3, 99 pp.

Liu, J., J. A. Curry, H. Wang, M. Song, and R. M. Horton, 2012: Impact of declining Arctic sea ice on winter snowfall. Proc. Natl. Acad. Sci. USA, 109 (11), 4074-4079, doi:10.1073/ pnas.1114910109.

McCarthy, G., and Coauthors, 2012: Observed interannual variability of the Atlantic meridional overturning circulation at $26.5^{\circ}$ N. Geophys. Res. Lett., 39, L19609, doi:10.1029/2012GL052933.
Osborn, T. J., 2011: Winter 2009/2010 temperatures and a record breaking North Atlantic Oscillation index. Weather, 66, 19-21.

Rayner, D., and Coauthors, 2011: Monitoring the Atlantic meridional overturning circulation. Deep-Sea Res. II, 58, 17441753.

Reynolds, R. W., and T. M. Smith, 1994: Improved sea surface temperature analysis using optimum interpolation. J. Climate, 7, 929-948.

_ - N. A. Rayner, T. M. Smith, D. C. Stokes, and W. Wang, 2002: An improved in situ and satellite SST analysis for climate. J. Climate, 15, 1609-1625.

Robertson, A. W., C. R. Mechoso, and Y.-J. Kim, 2000: The influence of Atlantic sea surface temperature anomalies on the North Atlantic Oscillation. J. Climate, 13, 122-138.

Rodwell, M. J., D. P. Rowell, and C. K. Folland, 1999: Oceanic forcing of the wintertime North Atlantic Oscillation and European climate. Nature, 398, 320-323.

Rogers, J. C., 1996: Patterns of low-frequency monthly sea level pressure variability (1899-1986) and associated wave cyclone frequencies. Quart. J. Roy. Meteor. Soc., 122, 1385-1414.

Sinha, B., and R. Smith, 2002: Development of a fast coupled general circulation model (FORTE) for climate studies, implemented using the OASIS coupler. Tech. Rep. 81, National Oceanography Centre, Southampton, United Kingdom, $67 \mathrm{pp}$.

—, A. T. Blaker, J. J.-M. Hirschi, S. Bonham, M. Brand, S. Josey, R. S. Smith, and J. Marotzke, 2012: Mountain ranges favour vigorous Atlantic meridional overturning. Geophys. Res. Lett., 39, L02705, doi:10.1029/2011GL050485.

Sonnewald, M., J. J.-M. Hirschi, and R. Marsh, 2013: Oceanic dominance of interannual subtropical North Atlantic heat content variability. Ocean Sci. Discuss., 10, 27-53, doi:10.5194/ osd-10-27-2013.

Strey, S. T., W. L. Chapman, and J. E. Walsh, 2010: The 2007 sea ice minimum: Impacts on the Northern Hemisphere atmosphere in late autumn and early winter. J. Geophys. Res., 115, D23103, doi:10.1029/2009JD013294.

Sutton, R. T., and M. R. Allen, 1997: Decadal predictability of North Atlantic sea surface temperature and climate. Nature, 388, 562-567.

— European climate in the 1990s. Nat. Geosci., 5, 788-792, doi:10.1038/NGEO1595.

Taws, S. L., R. Marsh, N. C. Wells, and J. Hirschi, 2011: Reemerging ocean temperature anomalies in late-2010 associated with a repeat negative NAO. Geophys. Res. Lett., 38, L20601, doi:10.1029/2011GL048978.

Valcke, S., L. Terry, and A. Piacentini, 2000: OASIS 2.4 user's guide. CERFACS, 85 pp.

Wilson, C., B. Sinha, and R. Williams, 2009: The influence of ocean dynamics and orography on Northern Hemisphere storm tracks. J. Climate, 22, 3689-3702. 